\title{
THE USE OF A LEARNING MANAGEMENT SYSTEM TO FACILITATE STUDENT-DRIVEN CONTENT DESIGN: AN EXPERIMENT
}

\author{
Riana Steyn ${ }^{1}$, Solly Millard ${ }^{2}$ and Joyce Jordaan ${ }^{3}$ \\ ${ }^{1}$ University of Pretoria, South Africa, 0002 \\ ${ }^{2}$ University of Pretoria, South Africa, 0002 \\ 3 University of Pretoria, South Africa,0002 \\ riana.steyn@up.ac.za
}

\begin{abstract}
.
Technology is everywhere, we only need to look around and observe the world around us. Teaching any course today cannot be done without some form of technology incorporated, if not the central point of delivering material and content to students.

Everywhere we look, students are sitting on their phones, or with tablets, why not allow students to use these devices to enhance their education, and learn something from the time they spent looking at a screen?

This paper explores this notion of allowing students to use a blackboard learning management system (LMS) as well as any other relevant technology and design their own "textbook chapter" based on a specific theme or topic provided to them. A hybrid approach was adopted as an experiment to see how the lecturers can use an LMS to improve their students' experience of using the LMS in an attempt to improve their own knowledge.

Students felt blackboard assisted them to understand the context and in particular felt that this assignment assisted them to understand the topic "use cases" better. In the end, the main goals were to ensure that students used technology to grasp the content and this was indeed the case.
\end{abstract}

Keywords: Blackboard - Hybrid learning - Learning management system - Student - Teaching approach 


\section{Introduction}

The approach to teaching has long been based on the model of handing a student a textbook which includes all the content required for the term, semester or even year. But in today's world where one cannot have any discipline free from technology, can this model still be followed? Technology is everywhere, we don't need a reference to state that, we only need to look around and observe the world around us. Going to a coffee shop or restaurant, it is almost scary to see how many people are busy with their phones and not talking to the person sitting opposite them. The same can be said for the classrooms. Everywhere we look, students are sitting on their phones, or with tablets, and even the "uncool" student has a laptop... who uses that any more... On a more serious note, this is reality for us as educators, the reality of the students we work with are "always on/ never off" as coined by Ashraff [1] and Pullan [2] and these are the students we see every day. Linking onto this, Turpie [3] said that "new technology and digital media engage young people from the day they enter the world" in other words, they are almost born with a phone in the hand. The students referred to here are the millennials which are "the first generation growing up with the internet" [2].

A non-academic reference on Wikipedia calls these students generation $Z$ [4]. This is the "new era" we are living in and it will only get better or "worse" depending on your viewpoint. So why not allow students to use these devices to enhance their education, and learn something from all the time they spent looking at a screen? Puttnam [5] rightfully states that "if we want to win back the trust of young people, we need to engage far more effectively with their world - learn to view technology, and the way in which they relate to it - through their eyes." Why not use the time spent on screens more productively and allow them to create their own learning material, their own e-books, which are increasingly used throughout the world [6].

Many universities in western countries are forced to engage in a blended-learning environment where technology-mediated learning and face-to-face sessions have to merge [7]. Kirkwood and Prince [8] also noted that technology is no longer a field only for the enthusiasts or novel users, all lecturers should engage with technology. Laurillard [9] realised the importance to understand this new context of technology and mention that we should find means to embed our understanding of technology with the existing classroom. As tertiary education institutions we have to find ways of not just asking students to use technology to replicate known content, which seems a bit historic, but allow them to use these technologies in "disruptive" ways [5], even if that means to allow them to create their own content which they would then use to grasp the concepts better. Davidson, Major and Michaelsen [10] talks about the notion of getting students to become "active participants in the learning process", and not 
just having them sit in a classroom, listening to a lecturer and then repeating the theory back to the lecturer. This paper explores this notion of allowing students to use a blackboard learning management system (LMS) as well as any other relevant technology and design their own "textbook chapter" based on a specific theme or topic provided to them. A hybrid approach was adopted as an experiment to see how the lecturers can use an LMS to improve their students' experience of using the LMS in an attempt to improve their own knowledge.

The research question addressed in this paper is: can student learning increase from using a LMS to build their own content?

This paper will firstly discuss literature concerning hybrid learning approaches and collaborative learning after which the LMS used will be introduced. This paper will focus on the tools used in creating the "own" textbook chapter, as a means to gain a better understanding of the student's experience of the project. It will also see whether or not the students felt that there was value in building their own content and if such an approach enhanced their learning experience. The literature section will be followed by the methodology section after which the data analysis will be discussed and then this paper will conclude.

\section{$2 \quad$ Background}

\subsection{Hybrid learning approach}

Teaching any course today cannot be done without some form of technology incorporated, if not the central point of delivering material and content to students [11].

Blended learning, hybrid learning, e-learning ... which one it is? According to Moodley, Singh [11], there are numerous terms which in the end means the same approach. Bonk and Graham [12] defines blended learning as the combination of "face-to-face instructions with computer-mediated instruction". Bender [13] talks about hybrid learning, where a course that has face-to-face classes on campus, has an additional web-component linked to the course. Woods, Baker and Hopper [14] confirms this by talking about web-based augmentation of the traditional classroom setting. This way one can continue with the class even when the class time or contact time has stopped. Bender [13], Rosenberg [15] and Wilson [16] talks of the best of both worlds, this phenomenon of combining physical classroom interactions with some sort of web component.

Some of the benefits which hybrid learning can bring about is noted as an improvement to large classroom efficiency, increase in student-led learning approaches, improvement of the overall student morale and satisfaction, student achievement and skills acquisition is enhanced and it even seem as if withdrawal and absenteeism is reduced [14]. They continue to say that in the future all institutions will engage in what they call a $90-10$ rule, thus there will not be $100 \%$ face-to-face or $100 \%$ online but a mix of these two approaches. 
Laurillard [9] says one must focus on the traditional learning theory which basically says "what it takes to learn". Almost forget all the other jargon, and come back to the basics of teaching and learning and ask what it takes to learn. She continues to say that the adaption of technologies for learning should ultimately address this question.

According to Bender [13] there are certain characteristics which one has to take into account when working with students and incorporating a hybrid approach. These characteristics are:

- Independence and responsibility: Insecure students prefer more contact time with a lecturer and receive more authoritative guidance from the lecturer;

- Authoritarianism: An authoritarian student wants to listen to a lecturer who controls their teaching;

- Anxiety: An anxious student prefers highly structured environments and the more anxious, the bigger the desire for structure, support and encouragement. This tends to fluctuate throughout the semester;

- Intelligence: Students are seen as individual learners who bring various diversities into the classroom. Online learning also brings about different learning styles which should foster interactive learning and collaboration. It is seen that "good teaching should be cognizant of and tailored to the diversity of learners" [13];

- Motivation: Class room scenarios brings about peer pressure where online learning has a much bigger focus on self-reliance. Pullan [2] also notes that online learners tend to have a higher level of internal motivation. Lam, Lau [17] found that collaboration had a positive influence on motivation to learning. It would be interesting to see what the peer pressure effect was in the online group-assignment, as discussed in this paper;

- Introversion-extroversion: Introverts learn better when "fed" the information where extroverts learn better when working with their peers, typically also extroverts. However, on the flip-side, it seems as if introverts care much more for feedback than extroverts. It will be interesting to see if there is a correlation between introvert/extrovert and motivation as well as learning preferences in this paper;

- Gender: There seems to be a correlation between gender and achievement as it is said that females are more concerned about achievement than their male counterparts. Although this will make for an interesting study, this paper does not focus on gender studies and thus it will not be discussed in detail in this paper;

- Cognitive style: Learning facts tend to result in the need for contact time with the lecturer. It will be interesting to see how these students study and prefer to learn.

Continuing, Pullan [18] also notes the following characteristics for online learners: self-motivation, taking full responsibility and commitment. She continues to say that students today are hybrid learners, who take both campus-based and online courses. Thus one needs to realise that these students want to learn online, and they will do that anyway, the question is how we can include a hybrid learning approach into our "old" teaching approach to help the student better grasp the content.

Riffel and Sibley (2005) as cited in Wilson [16] found that online task-oriented assignments led to the same or in some cases better outcomes than just following the traditional method of lecturing. They continue to say that online students made use of 
the textbook in more cases, contacted other students for help more and more frequently worked in groups outside the classroom. Hybrid learning is seen as a technique which can be followed when introducing an active learning strategy [19] which in essence is allowing students to do certain activities and reflect on what they are doing. It is noted that teachers facilitate learning, but the students have to take responsibility for the actual learning. Although they defined active learning in the end as an in classroom activity, they also noted that it might continue outside of the classroom. This paper focuses on the notion of continuing the "in class teaching" with a combination of online notes and using features of Blackboard such as blogs and wikis, to facilitate further or continues learning.

This paper will focus on the following student characteristics to determine if these are relevant to the students:

- Responsibility / independence;

- Authoritarianism;

- Anxiety;

- Motivation;

- Introvert/extrovert;

- Cognitive style

There is however a flip-side to this approach, a blended learning or hybrid approach allows students to control their own time and place for learning [11], providing a proper infrastructure is the reason for successful blended learning approaches. This paper will further investigate the infrastructure used by the students to complete the assignment as this cannot be ignored especially in the South African context. sion.

This paper will from now on talk about a hybrid-approach to eliminate any confu-

\subsection{Learning management system}

Using a new technology can be a daunting task, this could even hinder the learning process or experience of using the system. However, over time and as one becomes more familiar with the technology, one can start to focus more on the content than on figuring out how the system works [13].

That being said, as mentioned earlier, the type of student we engage with today is very different from the student type of ten, even five years back. In 2009, Selwyn [20] notices that the 21 st century student learns in ways far removed from a formal setting such as a school or library. The processing skills which these student poses or have developed are essentially different from the "older" generation IT users. Already in 2001 Prensky [21] acknowledged that students think and process information on a totally different level, and that was nearly 17 years ago. Ashraf [1] mentions technosavvy and digitally-literate students, and linking them back to lecturers, "students demand excellent, inspired, interactive teaching" [1]. Students born between 1980 and 2000, called the Millennial generation [22], are the students sitting in our classrooms 
today. Pacansky-Brock [22] listed some interesting facts based on the American student of today: $94 \%$ of them are internet users, $94 \%$ have cell phones, and $83 \%$ are active users of social networking. Junco and Mastrodicasa (2007) as cited in Pullan [2] did a study amongst 7705 students which resulted in the following interesting statistics: $97 \%$ of students have computers, $76 \%$ use instant messaging, $34 \%$ of the students use websites as their primary source of news and thus emphasising the fact that "these student live online" [2].

This proof that students are engaged online most of the day, they are connected the whole time. It is for this reason that the researcher wanted to explore ways to use technology to grow the students' learning experience and knowledge as they are already connected.

An urban university in South Africa used Blackboard as their Learning management system (LMS). Blackboard was founded in 1997 [23] with their vision being "a user-friendly means by which college professors could put course information, including syllabi, reference sites and study guides on the web." It is estimated that in North America, Blackboard controls up to $80 \%$ of the academic course management system market.

There are numerous benefits of using Blackboard as the learning management system, as mentioned by Bradford, Porciello [23] which are:

- Increased availability;

- Access to the internet anytime and anywhere;

- Quick feedback;

- Improved communication;

- Tracking;

- Skills building.

Although Blackboard is the LMS used at the tertiary institution in focus, it is important to understand where Blackboard fits into the learning process when viewed from a pedagogical point of view. According to Laurillard [9] the learning process is characterised as:

- instructionism": influenced technology being used for presentations and testing;

- "constructionism": learning by constructing a model or object, thus using some kind of modelling tool programming language;

- "socio-cultural learning": using communities as a form of learning through discussion;

- "collaborative learning": combining constructionism and socio-cultural learning, using the technologies that support both.

She continues to say that if you apply all these approaches, you are following "the conversational framework" [9] which takes all the complexities of these pedagogies and shows the complexity of the learning process in one view. However, this paper will focus on the four learning processes as discussed above and indicate why certain aspects of the assignment were asked and why students had to complete the tasks in a specific way. 
Blackboard is the LMS used by the urban University where this study was conducted and is often referred to as ClickUp. Blackboard offers a vast number of functions, although the ones explored in this paper were wikis, blogs and group collaboration which have not been used actively yet in the course. The research approach follows.

\section{Research approach}

As part of a second year course called "Systems analysis and design" which is being presented at an urban University, one of the key concepts which students have to grasp and struggle with is "Use cases diagrams and narratives". Due to the fact that the lecturing staff realised that there is a shortage of well-structured textbook for their degree, the idea of creating a student-led textbook emerged. The students had to complete an assignment focusing specifically on Use cases. Some of the key objectives of the course are:

- Describe the benefits of use-case modelling;

- Define actors and use cases and be able to identify them from context diagrams and other sources;

- Describe the relationships that can appear on a use-case model diagram;

- Describe the steps for preparing a use-case model;

- Describe how to construct a use-case model diagram;

- Describe the various sections of a use-case narrative and be able to prepare one;

- Apply all the above study objectives to a case study and/or problem statement and/or real-life business problem.

To be able to address these objectives the students had to complete an assignment where they had to base their answer on "Use cases". This was an experiment to see how Blackboard can be used to assist in own content creation, if at all, and how students perceive the use of Blackboard in general. Using this course as a case study shed some light on how the LMS can be used to facilitate learning. A total number of 142 students were registered for this course and these students had to work in groups consisting of not more than 5 students, in the end there were 26 groups. Students selected their own group members although the one or two odd students who did not have groups were placed with groups of three students.

\subsection{Assignment background}

As part of the first deliverable of the assignment, students had to define use case diagrams by answering questions and writing a wiki on Blackboard. This used "collaborative learning" as they had to work as a group and write the Wiki collaboratively [9].

They also had to submit 10 Powerpoint slides which included their theory from their wiki to show how they would teach use case diagrams. Focusing on the "instructionism" [9]. 
They were asked to select a real-life business case which they investigated and analysed and "write-up" the case on not more than two pages. As part of this write up, they had to identify a business problem and typical requirements which could be used to develop a system for this business. They also had to make a 5 minute video introducing the business. This part of the assignment was done on Blackboard where each group had their own blog only they could see. This part mostly focused on "collaborative learning" [9], social interaction not just amongst group members but also with a business owner using various technologies to complete the assignment.

The second deliverable of the project involved them having to take their case and explain how one will draw a use case diagram based on the theory which they had to submit in deliverable 1 . They had to make a small video drawing use cases and explain how they went about to draw it, as if they are teaching the use case theory based on their case. This part mostly focused on a combination of "instructionism" from the student's side and "constructionism" [9] which allowed them to take the role of instructor and also allowed them to make a video and upload that to YouTube.

Lastly, they also had to do one narrative of one of the use cases which had to be a business critical use case, thus no CRUD (create, read, update or delete) use cases were allowed.

All the assignments were marked based on a rubric.

\section{$4 \quad$ Research methodology}

The students were asked to complete an online questionnaire based on their experience of the assignment after completing the assignment. This paper followed a positivist approach as it analysed the data obtained from the survey using statistical analysis techniques. The data was analysed using simple statistical techniques due to the low responses (only 59 responses), however this will allow patterns to emerge which will then be evaluated based on the literature and the rest of the findings [24].

After the assignments were completed, the students had to complete an online survey. In the end, 59 out of a possible 142 students completed a self-administered questionnaire which was analysed using quantitative methods. The data obtained from the questionnaire were exported into a CSV file, and send to the statistician, who assisted in analysing the responses using IBM SPSS Statistics version 23. The statistician and researcher were in continuous discussions during this process to ensure that the results reflected the actual responses to the questionnaires. All responses were analysed, based on the questions as well as the literature discussed earlier, in the following section.

\section{$5 \quad$ Data analysis and findings}

Of the total of 59 responses, 41 were male and 18 were females. 
$85 \%$ of the students were between 19 and 22 years old, however, considering that all students born between 1980 and 2000 are millennials as discussed earlier [22], all of the respondents were millennials.

The students had to provide the name of the degree which they are studying: almost all of the students that completed the survey study some of the technology degree with the majority of the respondents studying BCom Informatics, 64\%, and 20\% studying BIT Information Technology.

The majority of the students were enrolled for the module for their first time, $79 \%$.

Twenty five students considered themselves to be extroverts and 34 said they are introverts.

Turpie's [3] statement says that students today are engaged in new technology and prefer digital media. Firstly, to better understand whether infrastructure would have played a role in completing the assignment as well as the general connectivity level of these students, they were asked to give an indication of the nature of their connectivity. Table 1 shows that most students have access to the internet either through $\mathrm{Wi}-\mathrm{Fi}$ access or their own data. It was interesting to see that most of the students, $84.5 \%$ used Wi-Fi on campus and thus the value of providing Wi-Fi to these students were crucial. It does not seem as if connectivity was a problem in completing this assignment.

Table 1. Student connectivity

\begin{tabular}{|l|c|c|}
\hline \multicolumn{2}{|c|}{ At home (n=58) (\%) } & On Campus (n=58)(\%) \\
\hline WIFI only & 55.2 & 84.5 \\
\hline 3G / Own data & 31.0 & 13.8 \\
\hline No connectivity & 13.8 & 1.7 \\
\hline
\end{tabular}

They were then asked how connectivity played a role specifically in completing this assignment. This was asked according to the various aspects of the assignment. Thus the focus was on Blogs, wikis and group collaboration although youtube uploading was also a critical part of the assignment. One student did not answer the question. Although some students struggled on and off, it does not seem as if connectivity was a problem to complete the assignment.

Table 2. Connectivity to Blackboard

\begin{tabular}{|c|c|c|c|c|}
\hline & Blogs (\%) & Wiki (\%) & $\begin{array}{c}\text { Uploading } \\
\text { YouTube (\%) }\end{array}$ & $\begin{array}{c}\text { Group } \\
\text { laboration (\%) }\end{array}$ \\
\hline $\begin{array}{c}\text { No issues, thus connectivity was } \\
\text { amazing }\end{array}$ & 58.6 & 60.3 & 50.0 & 51.7 \\
\hline Struggled on and off & 34.5 & 36.2 & 36.2 & 41.4 \\
\hline $\begin{array}{c}\text { Could not connect during peak- } \\
\text { periods (between 8:00 and 19:00 daily }\end{array}$ & 6.9 & 3.4 & 10.3 & 5.2 \\
\hline Could not connect at all & 0 & 0 & 3.4 & 1.7 \\
\hline
\end{tabular}


Next they were asked when last they read a printed newspaper versus on their mobile device. This should show whether Turpie [3] was correct when he said young people are engaged with online media from the day that they are born.

Table 3. Frequency reading news paper

\begin{tabular}{|l|c|c|}
\hline Frequency & Printed news paper (\%) & $\begin{array}{c}\text { Newspaper on mobile } \\
\text { device (\%) }\end{array}$ \\
\hline Today & 5.1 & 37.3 \\
\hline In the last week & 22.0 & 33.9 \\
\hline During the last month & 59.3 & 16.9 \\
\hline $\begin{array}{l}\text { I have never read a news- } \\
\text { paper }\end{array}$ & 13.6 & 11.9 \\
\hline
\end{tabular}

According to Table 3 it is clear that most students read the newspaper using a mobile device to get news on current affairs, however, it was interesting to see that $59.3 \%$ of the students indicated that they have read a printed newspaper in the last month.

Students were asked if they watch TV, and if so, how, streaming, on a TV set or both options. Seventy three per cent of the students indicated that they do watch TV. Of the $73 \%$ or 43 respondents, 20 respondents said they watch TV on a TV set, five said they only watch TV through streaming and 18 said they watch TV both on a TV box and streaming.

Although the use of streaming was expected to be higher, it seems as if there is no clear preference as to how these students prefer watching TV.

To further understand the student profile, these students were asked if they love reading and if they prefer to read any printed format material such as books, textbooks etc. The majority of the students said they do not love reading, (56\% of the respondents). Although this number was quite high $71 \%$ of all the students indicated that they do read using printed format. The reason why is not clear.

About $80 \%$ of the students indicated that they have the prescribed textbook for the specific module which is only in available in printed format. Asking them if they used the textbook for the specific assignment their responses are visible in Table 4. It is important to note that 12 students did not answer this question.

Table 4. Textbook frequency

\begin{tabular}{|c|c|}
\hline Frequency & Response (\%) \\
\hline I Never use it & 12.8 \\
\hline Almost never & 38.3 \\
\hline Sometimes & 42.6 \\
\hline Almost every day & 4.3 \\
\hline Always & 2.1 \\
\hline
\end{tabular}


What is alarming is that just over $50 \%$ of the students never or almost never used the textbook, and almost $43 \%$ said they sometimes used it. This then raise the question, what did they use to get the information? They were then asked to what extent they used alternative resources, such as other printed textbooks, Google, Youtube or any other resources.

Table 5. Other resources used

\begin{tabular}{|c|c|c|c|c|c|}
\hline Frequency & $\begin{array}{l}\text { Other } \\
\text { textbook } \\
(\%)\end{array}$ & $\begin{array}{r}\text { Printed } \\
(n=57)\end{array}$ & $\begin{array}{l}\text { Google }(n=58) \\
(\%)\end{array}$ & $\begin{array}{l}\text { Wikipedia } \\
(n=58)(\%)\end{array}$ & $\begin{array}{l}\text { Youtube }(n=58) \\
\text { (\%) }\end{array}$ \\
\hline I Never use it & 31.6 & & 1.7 & 31.0 & 6.9 \\
\hline Almost never & 29.8 & & 1.7 & 20.7 & 19.0 \\
\hline Sometimes & 33.3 & & 32.8 & 30.0 & 35.5 \\
\hline Almost every day & 3.5 & & 25.9 & 6.9 & 20.7 \\
\hline Always & 1.8 & & 37.9 & 10.3 & 19.0 \\
\hline
\end{tabular}

Focusing specifically on Blackboard and the assignment at hand, the students were asked to what extent they used the following resources for this assignment. The most significant finding is the fact that Google was the most used resource, (64\%) which in fact is not a surprise, this is what we all do when we struggle with something, we "Google it". Under other, some students did mention that they used the lecture notes provided (6 respondents).

Other resources which the students listed included the lecture slides as well although only six students referred to these. It is clear from Table 5 that electronic resources, such as Google, Youtube or Wikipedia were used to better understand the specific topic.

The students then had to rank who they go to first for assistance. The results in Table 6 clearly show that they approach group members first. What was interesting was that students will rather go to Youtube before asking the lecturers, proving their reliance on technology. This could also be due to accessibility which is easier to YouTube than to the lecturer.

Table 6. Who are approached for help?

\begin{tabular}{|l|c|}
\hline Who/where the go to for help & Position Ranked \\
\hline My group members & 1 \\
\hline Assistant lecturers & 2 \\
\hline Fellow class mates & 2 \\
\hline YouTube & 3 \\
\hline Lecturer & 4 \\
\hline
\end{tabular}




\begin{tabular}{|l|l|}
\hline Textbook & 5 \\
\hline Library & 6 \\
\hline
\end{tabular}

When asking the students how they felt to approach a business in the real-world, and cross referencing this to introverts/extroverts, there was a significant association between introvert/extrovert and emotions experienced when they have to talk to someone in a real business $(\chi 2(1)=0.021)$. This showed that more extroverts were excited and enthusiastic, to talk to a real life business, than was expected under the assumption of no association.

Asking the students how they prefer to learn, Table 7 gives a clear overview of how students prefer to learn. All the students answered the question. Grouping agree and strongly agree together, $88 \%$ said they prefer practicing the diagrams by actually drawing it, similarly, $88 \%$ said tutor sessions helped them a lot where the tutors also drew the diagrams with them. Almost $82 \%$ said collaborating with friends, while $80 \%$ of the students prefer going to Youtube to understand difficult concepts and are also using Clickup (Blackboard) extensively. The percentages of students who indicated that they learn through Attending classes, Reading the textbook and working through the theory only were far below $80 \%$ ( $(71 \%, 66 \%$ and $53 \%$ respectively). The interesting part of these results were that using technology was not the first choice, but tutor session and collaboration.

Table 7. I prefer learning through:

\begin{tabular}{|c|c|c|c|c|}
\hline I learn easier through: & $\begin{array}{c}\text { Strongly } \\
\text { disagree (\%) }\end{array}$ & Disagree (\%) & Agree (\%) & $\begin{array}{l}\text { Strongly } \\
\text { agree (\%) }\end{array}$ \\
\hline Attending classes & 1.7 & 27.1 & 55.9 & 15.3 \\
\hline Reading the textbook & 3.4 & 30.5 & 50.8 & 15.3 \\
\hline Working through the theory only & 3.4 & 44.1 & 47.5 & 5.1 \\
\hline $\begin{array}{l}\text { Youtube difficult concepts to un- } \\
\text { derstand them better, thus I watch } \\
\text { videos }\end{array}$ & 6.8 & 13.6 & 40.7 & 39.0 \\
\hline $\begin{array}{l}\text { Practicing drawing the diagrams } \\
\text { myself, thus working through numer- } \\
\text { ous case studies }\end{array}$ & 1.7 & 10.2 & 44.1 & 44.1 \\
\hline Using Clickup Extensively & 1.7 & 18.6 & 49.2 & 30.5 \\
\hline $\begin{array}{l}\text { Collaborating with my fellow stu- } \\
\text { dents and discussing the work }\end{array}$ & 6.8 & 11.9 & 40.7 & 40.7 \\
\hline Tutor sessions & 1.7 & 10.2 & 37.3 & 50.8 \\
\hline
\end{tabular}

These results were similar to the findings in Table 6. The tutor sessions are presented by the assistant lecturers, thus explaining why tutor sessions and assistant lecturers featured similarly in "who I asked for help" as well as "how I prefer to learn". 
It is interesting that authoritarianism, where students prefer to sit in a class room and have their teaching controlled by a lecturer does not seem to be applicable for a lecturer but rather for a tutor or assistant lecturer.

Students were asked how they experienced the assignment of being able to design their own textbook. $64 \%$ said they felt the assignment helped them to understand the topic of use cases better, $63 \%$ said they were able to apply the theory to their practical drawing of the use cases and only $54 \%$ said that this assignment helped them to better analyse a business. The main focus of this paper, being Blackboard was evaluated by asking the students how they felt about using the different parts of blackboard for the assignment $(\mathrm{n}=57)$.

Table 8. Experience using Clickup (Blackboard)

\begin{tabular}{|l|c|c|c|}
$\begin{array}{l}\text { Your experience using the following } \\
\text { Clickup tools }\end{array}$ & Easy to use (\%) & $\begin{array}{c}\text { Neutral feeling } \\
\text { towards } \\
\text { gy (\%) }\end{array}$ & $\begin{array}{c}\text { Did not like it at } \\
\text { all (\%) }\end{array}$ \\
\hline Wikis & 50.9 & 24.6 & 24.6 \\
\hline Blogs & 43.9 & 31.6 & 24.6 \\
\hline $\begin{array}{l}\text { Uploading video to Youtube (adding } \\
\text { link) }\end{array}$ & 66.7 & 24.6 & 8.8 \\
\hline Working as a group on the same blog & 40.4 & 38.6 & 21.1 \\
\hline Making business case video & 54.4 & 31.6 & 14.0 \\
\hline Video to illustrate drawing use cases & 56.1 & 28.1 & 15.8 \\
\hline The use of Clickup itself & 73.7 & 24.6 & 1.8 \\
\hline
\end{tabular}

From Table 8 above it seems as if the majority of the students (76\% or more) found working on Blackboard easy or had a neutral feeling towards it. There were, however, students who did not like it at all, (25\% for wikis; $25 \%$ for blogs; only 1 student said he/she did not like Clickup itself). $74 \%$ of the students said overall that Clickup (Blackboard) itself was easy to use, which in the end, means that using Clickup (Blackboard) for this assignment was a good idea.

The researchers then wanted to see if there was a correlation between these experiences and their understanding of the topic uses cases. There was a moderate evidence of an association between uploading their videos onto Youtube and how students viewed doing the assignment as an auxiliary tool to understand the topic better (Fisher exact test $=0.081$ ). The same was true for Making business case video (Fisher exact test $=0.079$ ) and making the video to illustrate drawing use cases (Fisher exact test $=$ 0.070). Thus it seems as if the video part of the assignment did have an effect on whether the students believed that it to improve their understanding of use cases. The reason why is not clear however this might make for an interesting future study.

The students had to say what emotions they felt when receiving and doing this assignment, which is essentially designing your own content. Of the 57 students who 
completed the question $25 \%$ said they were excited, $37 \%$ said they felt responsible to ensure that the content was accurate, $18 \%$ said they were more motivated to do well, $10 \%$ said they felt anxious and $10 \%$ said they were not interested at all. Thus the majority of the students did seem to enjoy doing the assignment and take responsibility for doing well. Linking back to the characteristics of the students, it is interesting to see that a large percentage of the students felt responsible to ensure the content was accurate. It is also interesting to see that the options "motivation" and "anxious" were also selected by some students.

In the end, the students were asked three questions to see the overall picture. The first question was: if they were given practical examples in an electronic format, what would they rather prefer. 50\% said they would prefer the electronic version, $28 \%$ said they still prefer the classroom interaction with the lecturer, $7 \%$ only used ClickUp for subject information and $15 \%$ said they still prefer a printed textbook.

The second focus question was if they thought using Clickup (Blackboard) assisted them in creating their own content for the theme "use cases". $76.7 \%$ of the 56 respondents who answered the question said "yes". The last question asked if they thought doing this assignment helped them to understand the topic use cases better, and in the end, $92 \%$ of the 56 students said "yes".

\section{Discussion}

A large number of research endeavours are currently focusing on technology and the classroom or hybrid learning, and this paper is no exception. This paper set out to see if Blackboard as an LMS can be used to assist students to learn through own content creation and thus the research questions addressed in this paper is: can students benefit from using a LMS to build their own content?

Initiated as an experiment as part of a hybrid teaching approach the reserachers wanted to see if the students can take responsibility and ownership of their content and design a textbook based on their own knowledge. Focusing on the characteristcs of a student as determined in the literautre review, it seemed as if the folloiwng characteristics were indeed the determining factors for these students.

- Responsibility / independence - Students felt responsible to ensure the content was correct;

- Authoritarianism - not necessarily from lecturers but students did want tutor or assistant lecturer's help more as part of their learning approach;

- Anxiety - some students did say they felt anxious both for approaching the business world, which was more the introverts and anxious to do an assignment in a completely different way;

- Motivation - the students were motivated which goes hand in hand with taking responsibility;

- Introvert/extrovert - the extroverts were excited and enthusiastic, to talk to a real life business. 
- Cognitive style - This might be the biggest determining factor as one had to determine how these students prefer to lean and in the end, this is their cognitive style of learning:

- Practicing the diagrams by actually drawing it;

- Attending tutor sessions;

- Collaborating with friends;

- Going to Youtube to understand difficult concepts;

- Using Clickup (Blackboard) extensively;

- Google if you don't know.

Seeing if the assignment helped them to learn better, they felt that the assignment did help them understand the topic of use cases better and that they were able to apply the theory to their practical drawing of the use cases although a smaller percentage mentioned that the assignment helped them to better analyse a business.

In the end the aim was to see if student can benefit from such an approach, and the answer was an overwhelming yes. Students felt Blackboard assisted them to understand the context and in particular students felt that this assignment assisted them to understand the topic "use cases" better. In the end, the main goals were to ensure that students used technology and actually grasped the content better.

\section{$7 \quad$ Conclusion}

As educators, we have no choice but to adapt our learning approaches to engage more with the students. This assignment was an experiment and in the end it seems as if the students did benefit and actually enjoyed using technology to complete the assignment. The students sitting in front of us today don't necessarily want a manual to teach them how to do something, they want to try and figure it out themselves which is exactly what this assignment was. Can we do it again, definitely; did we learn lessons, for sure; but in the end this was a first step to embrace a hybrid learning approach to see if it can facilitate own content creation by students. Try something new, make mistakes, learn lessons but at least show the students that you are trying and wiling to engage with their world!

\section{Bibliography}

1. Ashraf, B., Teaching the Google-eyed YouTube generation. Education and Training, 2009. 51(5/6): p. 343 - 352.

2. Pullan, M.C., Student support services for millennial undergraduates. Journal of educational technology systems, 2009. 38(2): p. 235 - 253.

3. Turpie, J., Creative engineers, in CreativityMoneyLove: Learning for the 21ste Century, J. S.H. Shelagh Wright, J. Kieffer, and J. Newbigin, Editors. 2012.

4. Wikipedia. GEneration Z. 2017 [cited 20179 February 2017]; Available from: https://en.m.wikipedia.org/wiki/generation_Z. 
5. Puttnam, L., Creative learning through technology, in CreativityMoneyLove: Learning for the 21st Century, S.H. Shelagh Wright, J., Kieffer, J. \& Newbigin, J., Editor. 2012: Online.

6. Guedet, G., et al., Collective design of an e-textbook: Teachers' collective documentation. Journal of Mathematics Teacher Education, 2016. 19(2): p. 187 - 203.

7. Kirkwood, A. and L. Price, Learners and learning in the twenty-first century: what do we know about students' attitudes towards and experiences of information and communication technologies that will help us design courses? Studies in Higher Education, 2005. 30(3): p. 257-274.

8. Kirkwood, A. and L. Prince, Technology-enhanced learning and teaching in higher education: what is 'enhanced' and how do we know? A Critical literature review. Learning, media and technology, 2014. 39(2): p. 6 - 36.

9. Laurillard, D., The Pedagogical challenges to collaborative technologies. Computersupported Collaborative learning, 2009. 4: p. 5 - 20.

10. Davidson, N., C.H. Major, and L.K. Michaelsen, Small-Group learning in higher education - cooperative, collaborative, problem-based and team-based learning: An introduction by Guest editors. Journal on Excellence in College teaching, 2014. 25(3\&4): p. 1 - 6.

11. Moodley, P., R.J. Singh, and J. Cloete, Exploring student perceptions of using the learning management system and social media for blended learning at a rural University Progressio, 2015. 37(1): p. 68 - 82.

12. Bonk, C.J. and C.R. Graham, The handbook of blended learning: Global perspectives, Local designs. 2006, San Francisco, CA: Pfeiffer.

13. Bender, T., Discussion-based online teaching to enhance student learning: Theory, Practice, and Assessment. 2nd Edition ed. 2012, Virginia, USA: Stylus Publishing, LLC. 256.

14. Woods, R., J.D. Baker, and D. Hopper, Hybrid structures: FAculty use and perception of web-based courseware as a supplement to face-to-face instruction. Internet and higher education, 2004. 7: p. 281 - 297.

15. Rosenberg, M.J., Knowledge management and learning: Perfect togeher, in Trends and issues in instructional design and technology, R.A. Reiser and J.V. Dempsey, Editors. 2012, Pearson: Boston, MA.

16. Wilson, R.W., In-class-online hybrid methods of teaching planning theory: Assessing impacts on discussion and learning. Journal of planning education and research 2008. 28: p. $237-246$.

17. Lam, L., N. Lau, and L.C.W. Ngan. An investigation of the factors influencing student learning motivation with the facilitation of cloud computing in Higher education context of Hong Kong. in Hybrid learning: Theory, application and practice. 2013. Toronto, Canada.

18. Pullan, M.C., Student support services for millennial undregraduates. Journal of Educational technology systems, 2010. 38(2): p. 235 - 251.

19. Mitchell, A., S. Petter, and A.L. Harris, Learning by doing: Twenty successful active learning exercises for Information systems courses. Journal of Information technology education: Innovations in Practice 2017. 16: p. 21 - 26.

20. Selwyn, N., The digital native - myth and reality. Aslib Proceedings: New Information perspectives, 2009. 61(4): p. 364 - 379.

21. Prensky, M., Digital natives, digital immigrants. Part 1. On the Horizon, 2001. 9(5): p. 1 6.

22. Pacansky-Brock, M., Best Practices for Teaching with Emerging technologies. 2013, New York, NY 161: Routledge.

23. Bradford, P., et al., The blackboard learning system: the be all and end all in educational instruction. Journal of Educational technology systems, 2007. 35(3): p. 301 - 314. 
24. Oates, B.J., Researching information systems and computing. 2006, London: SAGE Publications Ltd. 341. 


\section{Annexure A}

Questionnaire layout -Blackboard paper

Respondent number

\section{Personal Information}

I hereby give consent that I am willingly completing this questionnaire and I was not forced to complete this

a) Yes

b) No

1. Gender

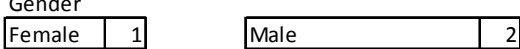

2. How old are you? ................................... years

3. Degree

\begin{tabular}{|l|r|}
\hline BCom Informatics & 1 \\
\hline BEd
\end{tabular}

BEd - FET: General

BIS - Information Science

BIT - Information Technology

BSc-Geoinformatics

BSc Information Technology - Information and

Knowledge Systems

Other (specify)

4. Number of Years enrolled for degree

5. I consider myself to be an:

Introvert "a person who tends to turn inward mentally. Introverts

sometimes avoid large groups of people, feeling more energized by time

alone"

Extrovert "a person concerned more with practical realities than with inner

thoughts and feelings; being concerned with the social and physical

environment"

6. I Learn easier through:

\begin{tabular}{l} 
I Learn easier through: \\
\cline { 2 - 5 }
\end{tabular}




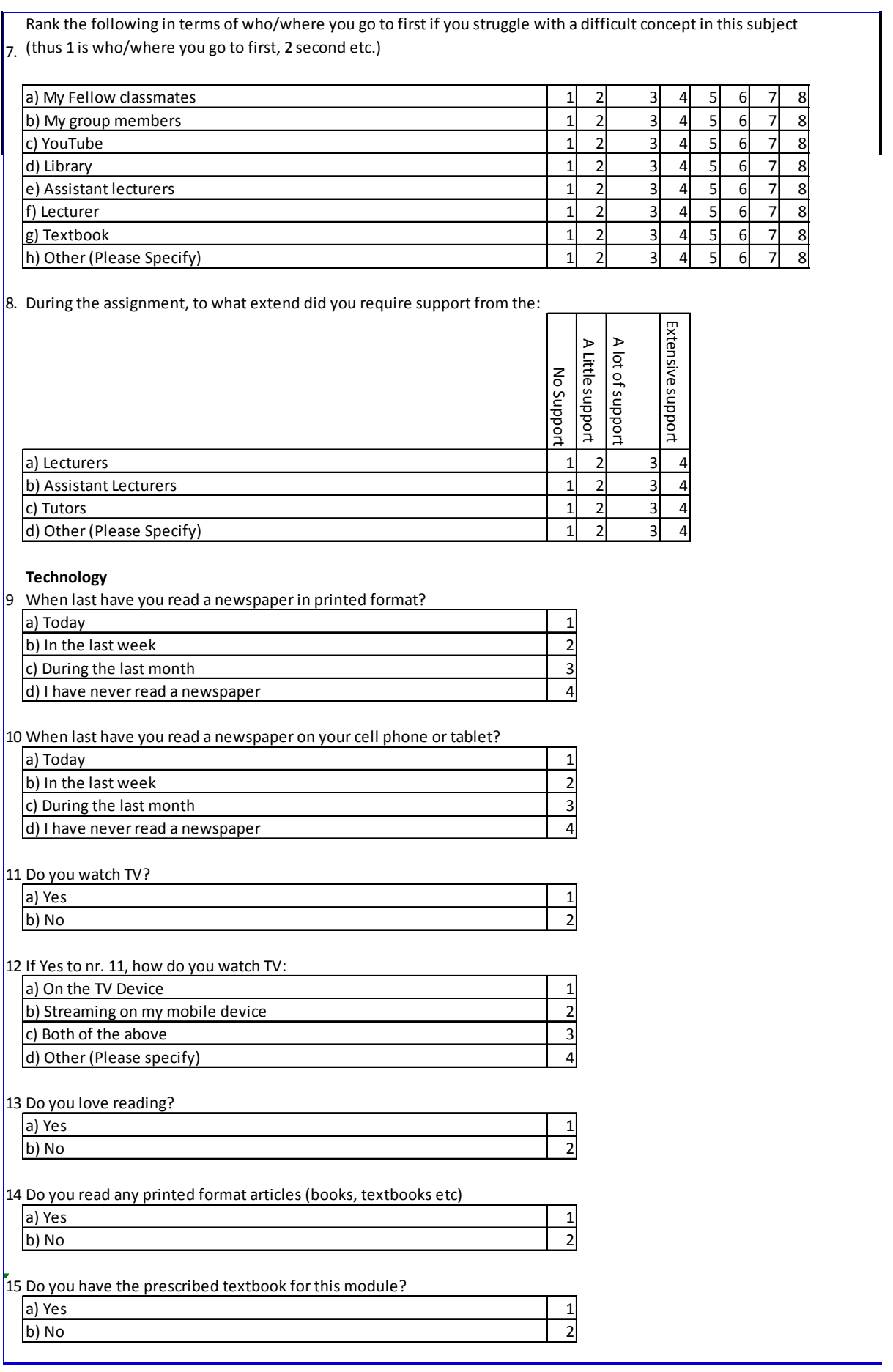




\begin{tabular}{l}
\hline 16 If yes to 15, When last did you open it up \\
\begin{tabular}{|l|r|}
\hline a) Today / a day ago & 1 \\
\hline b) A week ago & 2 \\
\hline c) Two weeks ago & 3 \\
\hline d) a Month ago & 4 \\
\hline e) I have never opened the textbook & 5 \\
\hline
\end{tabular}
\end{tabular}

17 If yes to 15, To what extend did you use the textbook for this assignment?

\begin{tabular}{|l|r|}
\hline a) I never used it & 1 \\
\hline b) Almost never & 2 \\
\hline c) Sometimes & 3 \\
\hline d) Almost every day & 4 \\
\hline e) Always & 5 \\
\hline
\end{tabular}

18 To what extend did you use the following resources for this assignment?

\begin{tabular}{|c|c|c|c|c|c|}
\hline & 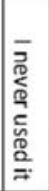 & 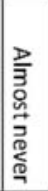 & 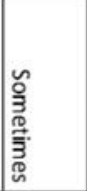 & 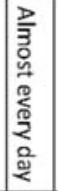 & 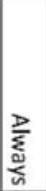 \\
\hline a) Other printed books & 1 & 2 & 3 & 4 & 5 \\
\hline b) Google & 1 & 2 & 3 & 4 & 5 \\
\hline c) Wikipedia & 1 & 2 & 3 & 4 & 5 \\
\hline d) YouTube & 1 & 2 & 3 & 4 & 5 \\
\hline e) Other (Please specify) & 1 & 2 & 3 & 4 & 5 \\
\hline
\end{tabular}

19 Being able to "design" a textbook for use cases allowed me to (select all relevant options)
a) Understand the theory behind use cases better
b) Being able to apply the theory to the practical drawing of use cases
c) Understand how to analyse a business better
d) Know which questions to ask a business owner when trying to identify
requirements
e) Understand the importance of systems in the business environment

20 Did the notion of having to talk to someone in a "real" business setting make you feel

\begin{tabular}{|l|r|}
\hline a) Stressed & 1 \\
\hline b) Anxious & 2 \\
\hline c) Intimidated & 3 \\
\hline d) Rather avoided it & 4 \\
\hline e) Excited & 5 \\
\hline f) Enthusiastic, could not wait to start & 6 \\
\hline
\end{tabular}

21 If I were given practical examples in an electronic format, I would rather study using the
a) Electronic version
b) Still prefer a prescribed printed textbook
c) Still prefer classroom interaction with the lecturer
d) Only use Clickup for subject information

22 How do you connect to the internet at home?

\begin{tabular}{|l|r|}
\hline a) Wifi Only & 1 \\
\hline b) 3G / own data & 2 \\
\hline c) No connectivity & 3 \\
\hline
\end{tabular}

23 How do you connect to the internet on campus?
a) Wifi Only
b) $3 G$ / own data
c) No connectivity

24 Have you ever used Tshwane free wifi for your studies?
a) Yes
b) No 


\begin{tabular}{|c|c|c|c|c|}
\hline \multicolumn{5}{|c|}{25 How did connectivity play a role in uploading your assignment for the following activities? } \\
\hline & 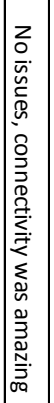 & 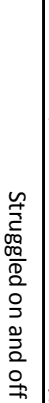 & 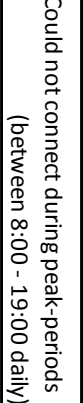 & 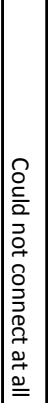 \\
\hline a) Blogs & 1 & 2 & 3 & 4 \\
\hline b) Wiki & 1 & 2 & 3 & 4 \\
\hline c) Uploading YouTube & 1 & 2 & 3 & 4 \\
\hline d) Collaborating as a group & 1 & 2 & 3 & 4 \\
\hline
\end{tabular}

26 What did you use to record your group's video?

a) Cellphone

b) Tablet

c) Video camera

d) Other (Please specify)

27 If you used your cellphone for the recording, which cellphone do you have?

a) Iphone

b) Samsung

c) Hauwei

d) Blackberry

e) Other (Please Specify)

28 Which software did you use to make your use case videos?

29 What was your experience with using the following tools on Clickup or Technology

\begin{tabular}{|c|c|c|c|}
\hline & 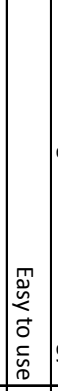 & 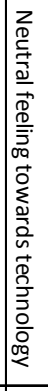 & 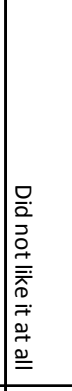 \\
\hline a) Wikis & 1 & 2 & 3 \\
\hline b) Blogs & 1 & 2 & 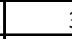 \\
\hline c) Uploading your video to youtube & 1 & 2 & 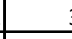 \\
\hline d) Working as a group on the same blog & 1 & 2 & 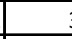 \\
\hline e) Making the business case video & 1 & 2 & 3 \\
\hline f) Making the video to illustrate drawing use cases & 1 & 2 & 3 \\
\hline g) The use of Clickup itself & 1 & 2 & 3 \\
\hline
\end{tabular}

GROUPWORK

30 Who was your client (Name of the business you analysed)?

31 How did you identify the business

32 How many group members were you 


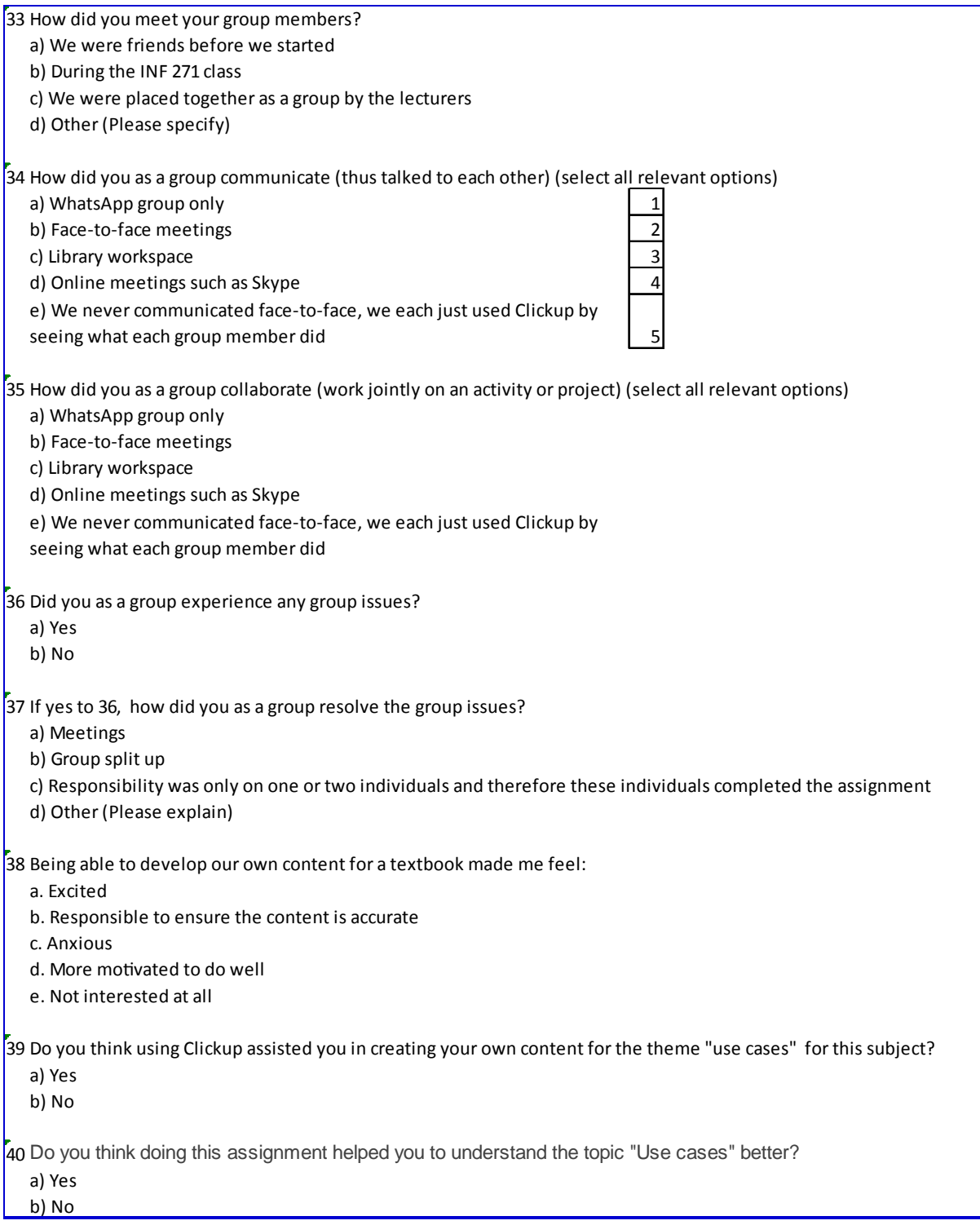

